\title{
Sweat testing in newborns positive to neonatal screening for cystic fibrosis
}

\author{
G Taccetti, F Festini, G Braccini, S Campana, M de Martino
}

Arch Dis Child Fetal Neonatal Ed 2004;89:F463-F464. doi: 10.1136/adc.2003.048934

Sweat chloride concentrations above $40 \mathrm{mmol} / /$ are unusual in newborns screened for cystic fibrosis and should be followed up. Centiles of sweat chloride concentrations in newborns positive to cystic fibrosis neonatal screening are presented. There are no significant correlations between age at sweat testing and sweat chloride concentration or quantity of sweat collected.

S weat testing is the mainstay of cystic fibrosis (CF) diagnosis. Sweat chloride concentrations are well defined in the post-neonatal period, and CF is diagnosed if they are higher than $60 \mathrm{mmol} / \mathrm{l} .{ }^{12}$ Hypertrypsinaemic newborns with chloride concentrations less than $60 \mathrm{mmol} / \mathrm{l}$ may still be affected by CF, as the chloride cut off is not well defined in the first few months of life. ${ }^{3-5} \mathrm{CF}$ has been diagnosed in hypertrypsinaemic newborns with borderline chloride concentrations $(40-60 \mathrm{mmol} / \mathrm{l})$ and below $40 \mathrm{mmol} / \mathrm{l}^{3-5}$ Recently published guidelines suggest that sweat testing can be performed after 2 weeks of age in infants weighing more than 3000 g. ${ }^{1}$ Experience with sweat tests in the first few weeks of life and in small and preterm babies is limited. ${ }^{3-6}$ Considering the increasingly widespread use of neonatal screening in various countries, we wish to report our experience with quantitative measurement of sweat electrolytes in newborns positive to neonatal screening. ${ }^{6}$

\section{SUBJECTS AND METHODS}

We screened all the newborns in Tuscany, a region with 3.5 million inhabitants and an annual birth rate of eight per thousand. We used the immunoreactive trypsinogen (IRT)/ IRT protocol on dried blood samples from July 1991 to May 1992, and the IRT/IRT with meconium lactase complementary test from May 1992. In 2001, we introduced a protocol based on IRT, lactase, and DNA analysis (31 mutations) because the high allelic heterogeneity found in Tuscany made the classic IRT/DNA approach inapplicable. ${ }^{6}$

Sweat testing was performed between 40 and 60 days of age. Ideally, hypertrypsinaemic newborns were tested when at least 30 days old and weighing at least $3000 \mathrm{~g}$.

Sweat was stimulated by pilocarpine iontophoresis at $1.5 \mathrm{~mA}$ for five minutes on a surface measuring $19 \mathrm{~cm}^{2}$, and then collected on dry filter paper on the same sized surface for 30 minutes. The minimum quantity was considered to be $60 \mathrm{mg}$ (sweat rate $1.05 \mathrm{~g} / \mathrm{m}^{2} / \mathrm{min}$ ). Sample pooling was avoided, and the chloride was assayed by the Gibson and Cooke method. ${ }^{12}$

\section{RESULTS}

We analysed the data from sweat tests performed on all 1003 newborns ( 557 girls, 446 boys) positive to neonatal screening out of the 335903 children born in the study region from l July 1991 to 31 December 2003.
In this period, 82 cases of CF were diagnosed; seven of them had meconium ileus and IRT above the cut off. There were five false negatives. CF incidence in Tuscany was $1: 3860$. In $7.1 \%$ of the subjects, the quantity of sweat collected was insufficient at the first attempt, and the full sweat test was repeated. No adverse effects, apart from a slight reddening of the skin, were observed. A total of 78 (7.7\%; 34 girls, 44 boys) of the 1003 newborns had chloride concentrations above the customary $60 \mathrm{mmol} / \mathrm{l}$ cut off and had clinical manifestations of the disease. In two other cases, blood spot genotyping alone allowed CF diagnosis: in one case, the sweat test was negative (genotype $2789+5 \mathrm{G} \rightarrow \mathrm{H}$ / $\mathrm{R} 1 \mathrm{17H})$, and in the other, the patient died and diagnosis was performed post mortem by DNA analysis.

Sixteen (1.6\%) of the 1003 newborns with borderline sweat chloride concentrations were followed over time, and the test repeated. Eleven subjects, born before our centre carried out blood spot genotyping, all had chloride concentrations below $40 \mathrm{mmol} / \mathrm{l}$ after a mean follow up period of 3.6 months. In the five subjects born subsequently, DNA was analysed and exocrine pancreatic function (stool chymotrypsin assay) studied. Two pancreatic sufficient subjects were identified as compound heterozygotes, and their sweat tests became positive over time. Three more subjects with a single mutation had normal pancreatic function, normal sweat tests, and at a year old were considered carriers. Thirty four newborns $(3.4 \%)$ had chloride concentrations between 30 and $39 \mathrm{mmol} / \mathrm{l}$. They were sent for clinical assessment to their practitioners without further tests being performed, and in the following 12 months none was sent back for suspected CF. In the 922 newborns who screened positive with chloride concentrations of $<60 \mathrm{mmol} / \mathrm{l}$ and who, to our knowledge, did not develop clinical manifestations of CF, the mean (SD) chloride concentration was 16.1 (7.06) $\mathrm{mmol} / \mathrm{l}$ (median 15; 95\% confidence interval 15.6 to 16.5). As the upper limit of normal sweat chloride in newborns is not well defined, we calculated the sweat chloride centiles (table 1).

We know the age at the time of the test, the birth weight, and the gestational age of the 922 hypertrypsinaemic subjects. The mean (SD) age at sweat testing was 65 (43) days (median 56; range 22-450). The mean (SD) quantity of sweat collected was 149.5 (48.9) mg (median 153; range 60-274). Only 39 of these subjects underwent sweat testing in the first 30 days of life: mean quantity of sweat $147.1 \mathrm{mg}$, mean chloride concentration $17.3 \mathrm{mmol} / \mathrm{l}$. Fifty two subjects underwent sweat testing after the fourth month: mean quantity of sweat $162.3 \mathrm{mg}$, mean chloride concentration $16.2 \mathrm{mmol} / \mathrm{l}$. These data are not significantly different from those of other hypertrypsinaemic subjects (Student's $t$ test, $\mathrm{p}>0.05$ ).

We noted no significant correlations between age at sweat testing and chloride concentration $(r=-0.039)$, age at sweat testing and quantity of sweat collected $(r=0.11)$, birth weight and chloride concentration $(r=-0.15)$, or gestational age and chloride concentration $(r=-0.14)$. 
Table 1 Centiles of chloride sweat concentrations in children positive to neonatal screening

\begin{tabular}{lllllllll}
\hline 3 rd & $10^{\text {th }}$ & $2^{\text {th }}$ & $50^{\text {th }}$ & $\mathbf{7 5 \text { th }}$ & 90th & 95th & 97th & 99th \\
\hline 7.6 & 9.6 & 11.8 & 15 & 19.9 & 25.5 & 30.4 & 34.3 & 40.8 \\
\hline
\end{tabular}

\section{DISCUSSION}

Hypertrypsinaemic subjects (at high risk of CF or carriers) should undergo sweat testing to complete diagnostic testing. As retesting is an important component of our screening procedure, it was only possible to carry out sweat testing in the first month in a limited number of cases. ${ }^{6}$ However, centres using the IRT/DNA protocol should be able to perform sweat testing at an early age. Although our data are numerically limited, they do not support the hypothesis that the quantity of sweat collected in the first month and the chloride concentration are different from those collected in the following three months. Furthermore, we found no correlation between age at sweat testing and chloride concentration or quantity of sweat collected. The first attempt at sweat testing was not satisfactory because of insufficient sweating in only $7.1 \%$ of cases. Sweat testing can be easily carried out by an experienced technician in the first few weeks of life without adverse effects. A local reddening of the skin is a normal reaction to pilocarpine iontophoresis. ${ }^{2}$

The established concentration of $60 \mathrm{mmol} / \mathrm{l}$ helped us to identify 78/81 (96\%) patients with CF. Chloride concentrations above $40 \mathrm{mmol} / \mathrm{l}$ are nevertheless unusual, and only $1 \%$ of newborns screened without CF had concentrations above this cut off point. Newborns with borderline sweat chloride concentrations (40-60 mmol/l) must be followed up with DNA analysis, investigation of exocrine pancreatic function, and repeated sweat tests until the diagnosis is clarified..$^{3-5}$ The slight possibility that some hypertrypsinaemic newborns affected by CF may have negative results on the sweat test must be considered, but this underlines the need, where possible, for protocols based on DNA analysis.

\section{ACKNOWLEDGEMENTS}

We thank the Telethon Foundation, Italy for grant GGP02205.

\section{Authors' affiliations}

G Taccetti, F Festini, G Braccini, S Campana, M de Martino, Cystic Fibrosis Centre of Tuscany, Meyer Pediatric Hospital, University of Florence, Florence, Italy

Correspondence to: Filippo Festini, Cystic Fibrosis Centre of Tuscany, Meyer Pediatric Hospital, University of Florence, via L Giordano 13, Florence 50132, Italy; filippo.festini@iol.it

Accepted 29 May 2004

\section{REFERENCES}

1 Baumer JH. Evidence based guidelines for the performance of the sweat test for the investigation of cystic fibrosis in the UK. Arch Dis Child 2003;88:1126-7.

2 Legrys VA. Sweat testing for the diagnosis of cystic fibrosis: practical considerations. J Pediatr 1996; 129:892-7.

3 Farrell PM, Koscik RE. Sweat chloride concentration in infants homozygous or heterozygous for F508 cystic fibrosis. Pediatrics 1996;97:524-8.

4 Padoan R, Bassotti A, Seia M, et al. Negative sweat test in hypertrypsinemic infants with cystic fibrosis carrying rare CFTR mutations. Eur J Pediatr 2002;161:212-15.

5 Massie J, Gaskin K, Van Asperen P, et al. Sweat testing following newborn screening for cystic fibrosis. Pediatr Pulmonol 2000;29:452-6.

6 Taccetti G, Festini F, Mergni G, et al. Neonatal screening for cystic fibrosis: the Tuscan experience. Pediatr Pulmonol 2003;25(suppl):221-2. 